\title{
ANALISIS PENGARUH CUSTOMER SERVICE EXPERIENCE TERHADAP BEHAVIOR INTENTIONS \\ (Survei pada Wisatawan Sebagai Tamu Individu yang Menginap di Sheraton Mustika Yogyakarta Resort and Spa)
}

\author{
Kendid Syahid \\ Rini Andari \\ Taufik Abdullah \\ Manajemen Pemasaran Pariwisata FPIPS UPI
}

\begin{abstract}
Sheraton Mustika Yogyakarta Resort and Spa strive to provide good service to the "in touch" service oriented so that guests experience a memorable service. In order to get the guests who willing to stay longer, recommending and repurchasing, then Sheraton Mustika Yogyakarta conduct stratergi namely Star Customer Experience. The purpose of this research is to describe the customer service experience as the independent variable $(X)$, describe of behavior intentions as the dependent variable $(Y)$ and analyze the effect of customer service experience towards behavior intentions. The method used in this research is descriptive and verification due to this research is conducted less than one year so this research is a cross-sectional method. The sampling technique used is systematic random sampling with a sample of 100 first-timer guests. The data analysis technique used is multiple regression. The results showed that the highest score in customer service experience is the sub-variables for the assessment of empathy while the lowest is recognition. The highest valuation for the variables dimensions of behavior intentions is repurchasing intention while dimension of willingness to recommend is the lowest. Simultaneously customer service experience significantly influence on behavior intentions.
\end{abstract}

Keywords: Customer Service Experience, Service Experience, Behavior Intentions, Behavioral Intention

\section{PENDAHULUAN}

Daerah Istimewa Yogyakarta (DIY) memiliki potensi tinggi untuk menarik kunjungan wisatawan. Dalam melakukan kegiatan wisata, wisatawan memerlukan akomodasi yang merupakan fasilitas utama pendukung suatu perjalanan wisata. Data Dinas Kebudayaan dan Pariwisata DIY dan Badan Pusat Statistik Yogyakarta menunjukan bahwa pertumbuhan wisatawan pengguna akomodasi di Yogyakarta terus meningkat. Pada tahun 2012 jumlah pengguna akomodasi mencapai 2.360.173 dan naik sebesar 1,06\% di tahun 2013. Salah satu akomodasi yang berkembang pesat adalah hotel. Hotel dapat dikategorikan menurut kelasnya yaitu hotel berbintang dan non bintang serta menurut pengelolaannya yaitu hotel yang dikelola secara mandiri, hotel jaringan nasional dan hotel jaringan internasional.

Salah satu hotel bintang 5 yang dikelola manajemen jaringan hotel inernasional yaitu Sheraton Mustika Yogyakarta Resort and Spa. Tingkat hunian kamar di Sheraton Mustika Yogyakarta mengalami peningkatan dari $53,83 \%$ pada tahun 2012 menjadi $58,70 \%$ pada tahun 2013 dan kamar yang terjual bertambah dari tahun 2012 sebanyak 26.402 menjadi 27.892 pada tahun 2013. (Sumber:Perhimpunan Hotel dan Restoran Indonesia PHRI DIY, 2014). Namun demikian terjadi penuruan pada first timer guest atau tamu individu yang pertama kali menginap di Sheraton Mustika Yogyakarta.

Berdasarkan data tingkat hunian tamu berdasarkan segmentasi pasar, tingkat hunian paling rendah berasal dari segmentasi pasar tamu individu first timer. Tamu individu first timer mengalami penurunan dari 33,76\% pada tahun 2012 menjadi $17,88 \%$ pada tahun 2013. (Sumber:Sales and Marketing Department Sheraton Mustika Yogyakarta). Manejemen Sheraton Mustika Yogyakarta menjelaskan bahwa tamu individu first timer menjadi perhatian oleh manajemen hotel dikarenakan adanya kecenderungan tamu tersebut untuk melakukan perilaku positif tertentu di masa mendatang atau setelah menginap.

Tabel 1 menunjukan terjadi penurunan perilaku tamu individu first timer yang ingin menginap lebih lama, bersedia merekomendasikan dan bersedia untuk kembali menginap. Secara teori pemasaran, ketiga perilaku tersebut disebut sebagai niat berperilaku atau behavior intentions. Dalam 
upaya meningkatkan behavior intentions, Sheraton Mustika Yogyakarta melakukan strategi pemasaran melalui Star Customer Experience yang secara teori pemasaran disebut sebagai customer service experience. Program Star Customer Experience (SCE) merupakan program marketing dalam rangka membuat tamu merasa ''WOW', Artinya mereka merasakan pengalaman yang berbeda dan dapat dikenang sehingga mereka puas dan dapat kembali lagi ke Sheraton Mustika Yogyakarta. Strategi pemasaran ini lebih menitikberatkan pada pelayanan yang maksimal sehingga menimbulkan kesan dan pengalaman yang baik di benak tamu. Berikut data survei yang dilakukan Sheraton Mustika Yogyakarta.

TABEL 1

Rekapitulasi Survei Tamu Individu Melalui Surat Elektronik Sheraton Mustika Yogyakarta

\begin{tabular}{|c|c|c|c|}
\hline \multirow[b]{3}{*}{ Tahun } & & & \\
\hline & \multicolumn{3}{|c|}{ Actual Guest Response } \\
\hline & $\begin{array}{c}\text { Stay } \\
\text { Longer }\end{array}$ & $\begin{array}{c}\text { Likelihood } \\
\text { to } \\
\text { Recommend }\end{array}$ & $\begin{array}{c}\text { Likelihood } \\
\text { to Return }\end{array}$ \\
\hline 2012 & $77.50 \%$ & $76.10 \%$ & $75,90 \%$ \\
\hline 2013 & $75,50 \%$ & $74,20 \%$ & $73,40 \%$ \\
\hline
\end{tabular}

Sumber: Front Office Department Sheraton Mustika Yogyakarta, 2014

Park (2010:8) mengungkapkan bahwa dengan memberikan pengalaman yang baik akan mempengaruhi penentuan behavior intentions yang positif. Sejalan dengan itu, Huang dan Hsu (2009:31) mengungkapkan bahwa pengalaman dimasa lalu akan berkontribusi secara positif dalam penentuan sikap di masa mendatang.

Berdasarkan penjelasan, maka penulis memilih judul untuk mengkaji penelitian mengenai "Analisis Pengaruh Customer Service Experience terhadap Behavior Intentions ", (Survei pada Wisatawan Sebagai Tamu Individu yang Menginap di Sheraton Mustika Yogyakarta Resort and Spa).

\section{KAJIAN PUSTAKA}

Pemasaran hotel menurut Sulastiyono (2008:265) terdiri dari berbagai aktivitas yang bertujuan untuk menarik calon pelanggan dengan memberi motivasi agar tertarik untuk membeli produk dan jasa pelayanan hotel. Hotel termasuk ke dalam industri jasa atau hospitality. Di dalam industri jasa, pengalaman merupakan bagian penting dalam terciptanya suatu pelayanan jasa yang baik (Pine dan Gilmore, 1999 dalam Lin dan Chiang, 2009:1). Dijelaskan Sandstrom et al (2008:118) bahwa customer service experience adalah keseluruhan dimensi nilai fungsional dan emosional yang dihasilkan dari berbagai macam pelayanan. Customer service experience tidak dapat terpisah dari peyedia jasa atau service provider. Service experience selalu bersifat personal, individual dan unik bagi setiap orang yang berbeda dalam situasi yang beragam yang artinya konsumen merupakan pihak yang juga berperan aktif dalam penciptaan suatu pengalaman jasa yang dirasakan.

Pengalaman jasa (service experience) merupakan interkasi yang terjadi antara penyedia jasa dengan konsumen saat proses penggunaan atau penawaran jasa berlangsung sehingga pengalaman jasa yang dirasakan pelanggan tidak dapat dipisahkan dari penyedia jasa atau service provider. Berry at al (2006:2) mengungkapkan 'The best service companies manage the emotional components of the customer service experience with as much rigor as they bring to the functional components." Maksudnya bahwa perusahaan jasa yang baik adalah perusahaan yang mengatur komponen emosi dari pengalaman jasa pelanggan sebanyak komponen yang bersifat fungsional.

Penelitian ini menggunakan customer service experience yang diusulkan Aisuebeogun (2007:98) yang mana customer service experience didefinisikan sebagai seperangkat isyarat yang mencakup komponen fungsional dan emosional yang terdiri dari enam dimensi yaitu organised, welcoming, recognition, communication, empathy dan helpful.

Smith dan Wheeler (2002:21) mengungkapkan bahwa customer experience berasosiasi dengan customer behavior. Behavior intentions pada dasarnya merupakan suatu sikap tertentu yang dilakukan seseorang di masa depan, dalam hal ini tamu hotel sebagai reaksi atau respon dari pelayanan jasa yang telah diterima.

Armitage and Conner (2001) dalam Huang dan Hsu (2009:30) bahwa 'behavioral intentions would generally lead to actual behavior' ' atau behavior intentions secara umum akan memimpin seseorang kepada perilaku yang sebenarnya. Perilakuperilaku tersebut seperti diungkapkan oleh Lin dan Chiang (2010:290) yaitu stay longer, willingness to recommend dan 
repurchasing intention yang menjadi dimensi untuk konsep atau variabel behavior intentions yang penulis gunakan untuk dalam penelitian ini. Ketiga indikator tersebut merupakan perilaku positif yang dipilih tamu setelah merasakan pengalaman pelayanan atau customer service experience.

Hipotesis yang diajukan dalam penelitian ini adalah "terdapat pengaruh antara customer service experience yang terdiri dari organised, welcoming, recognition, communication, empathy, dan helpful terhadap behavior intentions baik secara parsial maupun simultan. Dengan didikung oleh premis yang dinyatakan oleh Park dan Oh (2010:49) yang mengungkapkan bahwa Escapist experience secara positif mempengaruhi behavioral intention dan Kuruuzum dan Koksal (2010:10) mengungkapkan bahwa semakin positif pengalaman yang dirasakan pelanggan, semakin ingin pula ia merasakan kembali pelayanan jasa tersebut atau repurchasing intention.

\section{METODE PENELITIAN}

Objek dalam penelitian ini adalah tamu individu yang menginap di Sheraton Mustika Yogyakarta. Variabel bebas (variabel $\mathrm{X}$ ) yaitu customer service experience yang terdiri dari organised, welcoming, recognition, communication, empathy, dan helpful. Sedangkan untuk variabel terikat (variabel Y) yaitu behavior intentions yang terdiri dari stay longer, willingness to recommend dan repurchasing intention. Populasi dalam penelitian ini adalah seluruh tamu individu first timer.

Teknik sampling yang digunakan dalam penelitian ini adalah systematic random sampling, didapat sampel sejumlah 100 responden tamu individu first timer. Penelitian ini menggunakan pendekatan cross sectional karena dilakukan dalam waktu kurang dari satu tahun. metode yang digunakan dalam penelitian ini adalah metode penelitian deskriptif dan verifikatif dimana dalam penelitian ini akan diuji pengaruh customer service experience terhadap behavior intentions tamu Sheraton Mustika Yogyakarta.

Teknik pengumpulan data yang dilakukan penulis adalah dengan cara melakukan wawancara, observasi, kuisioner dan studi literatur. Untuk memperoleh hasil pengaruh customer service experience terhadap behavior intentions penulis menggunakan teknik analisis data regresi berganda (multiple regression).

\section{HASIL PENELITIAN DAN PEMBAHASAN}

Berdasarkan hasil penelitian dan tanggapan tamu individu, mengenai customer service experience, sub variabel empathy memiliki penilaian tertinggi $(17,26 \%)$ dikarenakan Sheraton Mustika Yogyakarta memiliki tiga prinsip utama yang dinamakan Starwood Cares yaitu care for associate, care for the guest dan care for community. Dalam hal ini sikap peduli diterapkan pada sikap empathy yang disampaikan staf kepada tamu dimana staf senantiasa memberikan kepedulian, empati dan rasa nyaman kepada tamu selama menginap. Sedangkan untuk penilaian paling rendah yaitu pada sub variabel recognition $(16,25 \%)$. Hal ini dikarenakan adanya kebutuhan fasilitas dan jasa tamu yang beragam sehingga menyulitkan staf untuk selalu menyadari kebutuhan jasa tamu yang berasal dari keperluan menginap yang berbeda.

Untuk variabel behavior intentions, Kontribusi penilaian paling tinggi yaitu pada repurchasing intention (47,19\%). Hal ini dikarenakan secara keseluruhan fasilitas dan layanan yang dirasakan tamu dinilai baik sehingga tamu bersedia untuk kembali menginap atau merasakan fasilitas dan jasa lainnya yang tersedia di Sheraton Mustika Yogyakarta. Sedangkan willingness to recommend $(6,29 \%)$ memiliki penilaian terendah dikarenakan Sheraton Mustika Yogyakarta sudah memiliki brand yang baik di benak konsumen sehingga tamu merasa tidak perlu merekomendasikan Sheraton Mustika Yogyakarta lagi.

Pengujian hipotesis secara simultan (Uji F/Tabel Anova) menunjukan bahwa nilai $\mathrm{F}_{\text {hitung }}=43,226$ dengan tingkat probabilitas sig. 0,000. Oleh karena nilai signifikansi 0,000 lebih kecil dari taraf signifikansi 5\% $(0,05)$ maka dapat dikatakan bahwa model fit dan dapat memprediksikan behavior intentions. Menurut perhitungan didapat Ftabel $=2,20$ atau $F_{\text {hitung }}>F_{\text {tabel }}$ yaitu 43,226 $>$ 2,20. Maka $\mathrm{H}_{0}$ ditolak dan Ha diterima. Secara keseluruhan atau simultan variabel independen customer service experience (X) yang terdiri dari organised, welcoming, recognition, communication, empathy dan helpful berpengaruh secara signifikan 
terhadap variabel dependen yaitu behavior intentions (Y).

Sedangkan secara parsial melalui uji t didapat hasil sebanyak 3 sub variabel yang memiliki nilai signifikansi lebih besar dari 0,05 dan $\mathrm{t}$ hitung $<\mathrm{t}$ tabel sehingga sub variabel tersebut tidak berpengaruh secara signifikan terhadap behavior intentions. Sub variabel yang tidak berpengaruh secara signifikan yaitu welcoming, recognition dan helpful sedangkan sub variabel organised, communication dan empathy memiliki pengaruh yang signifikan terhadap variabel behavior intentions.

Melalui hasil analisis regresi berganda didapat persamaan sebagai berikut:

$Y=a+b_{1} X_{1}+b_{2} X_{2}+b_{3} X_{3}+b_{4} X_{4}+b_{5} X_{5}+$ $\mathbf{b}_{6} \mathbf{X}_{6}$

$\mathrm{Y}=2,968+0,182 \mathrm{X} 1+0,088 \mathrm{X} 2+0,106 \times 3$

$+0,300 X 4+0,238 X 5+0,115 X 6$

Hasil analisis menunjukan nilai konstanta 2,968 artinya jika $\mathrm{x} 1, \mathrm{x} 2, \mathrm{x} 3, \mathrm{x} 4, \mathrm{x} 5, \mathrm{x} 6, \mathrm{x} 7$ diabaikan maka tingkat behavior intentions tamu Sheraton Mustika Yogyakarta adalah sebesar 2,968 atau $29,68 \%$. Untuk setiap kenaikan satu persen sub variabel $\mathrm{X}$ maka tingkat behavior intentions akan meningkat sebesar nilai pada persamaan regresi untuk setiap sub variabel.

\section{KESIMPULAN DAN SARAN}

Secara keseluruhan customer service experience yang dilaksanakan di Sheraton Mustika Yogyakarta sudah baik. Hal ini sesuai dengan tanggapan dan penilaian tamu terhadap customer service experience yang dirasakan tamu selama menginap. Hasil penelitian menunjukan bahwa customer service experience dapat mempengaruhi behavior intentions tamu Sheraton Mustika Yogyakarta. Namun dalam beberapa pelaksanaan masih terdapat kekurangan seperti pada welcoming, recognition dan helpful yang masih dinilai rendah oleh tamu. Oleh karena itu penulis menyarankan agar manajemen Sheraton Mustika yogyakarta meningkatkan kinerja pelayanan jasa terutama pada ketiga pelaksanaan pelayanan jasa tersebut melalui personalisasi penyampaian jasa kepada tamu sesuai kebutuhan tamu tersebut, mengetahui keperluan tamu menginap dengan menulis pada note sistem lightspeed yang digunakan. Dengan begitu, fasilitas, jasa dan layanan yang diberikan akan disesuaikan dengan keperluan tamu tersebut.

\section{DAFTAR PUSTAKA}

Aisuebeogun, Susan Edwards. 2007. Understanding Customer Experience and Its Impact within the Hotel Sector. Cranfield University.

Badan Pusat Statistik Kota Yogyakarta. 2014. Statistik Pariwisata Kota Yogyakarta-Tourism Statistics of Yogyakarta City. Diakses melalui: http://jogjakota.bps.go.id/?hal=publik asi detil\&id=7 pada 8 Juli 2014 19.23 PM

Berry, Leonard L et al .2006. Managing Service Experience Clues. Wharton: University of Pennsylvania.

Dinas Pariwisata Daerah Istimewa Yogyakarta. 2013. Statistik Kepariwisataan 2012. Yogyakarta: Disbudpar DIY.

Huang, Songshan dan Hsu, Cathy H.C. 2009. Effects of Travel Motivation, Past Experience, Perceived Constraint, and Attitude on Revisit Intention. Journal of Travel Research. 48, (01)., 29-44.

Kuruuzum, Ayse dan Koksal, Can Deniz. 2010. The Impact of Service Quality on Behavioral Intention in Hospitality Industry. International Journal of Business and Management Studies. 2, (01).

Lin, Chiang. 2009. The Influence of Store Environment on Perceived Experiential Value and Behavior Intention. Asia Pacific Management Review. 15(2) (2010) 281-299.

Park, Minkyung et al. 2010. Measuring the Experience Economy of Film Festival Participants. International Journal of Tourism Sciences, 10, (2), 35-54.

Sandstrom et al., 2008. Value in Use Through Service Experience Managing Service Quality. Emerald Group Publishing Limited. 18, (2), 112-126.

Smith dan Wheeler, Joe. 2002. Managing the Customer Experience. Great Britain: Pearson Education Limited.

Sulastyono, Agus. 2008. Manajemen Penyelenggaraan Hotel. Bandung:Alfabeta 